\title{
Understanding dualism through emotion: Descartes, Spinoza, Sartre
}

\author{
Entendiendo el dualismo a través de la emoción: \\ Descartes, Spinoza, Sartre
}

DANIEL O'SHIEL ${ }^{a}$

\begin{abstract}
This paper argues that a proper understanding of the epistemological and metaphysical issue of dualism can only be attained through a thoroughgoing analysis of human emotion. Indeed, it is no coincidence that three main thinkers on dualism, whether they were apparent proponents (Descartes), opponents (Spinoza), or had a somewhat ambiguous status (Sartre), were also heavily involved in understanding emotion. Ultimately, a proper comprehension of emotion shows the issue of dualism to be moot when it comes to our pre-reflective, everyday lives; dualism is a theoretical interest that shows how we must necessarily posit two essential realms - one of nature and one of consciousness - that are nevertheless always already entwined in prereflective and immediately lived experiences like emotion. In this manner, a proper understanding of emotion shows that dualism is not an issue on the everyday lived level, but certainly is on epistemological and metaphysical ones. On these levels, dualism is an essential tool that must be understood and used properly if one is to give a thoroughgoing account of human nature from a theoretical standpoint, where avoiding conflations between immediate and reflective experiences, as well as firstperson and third-person standpoints, is crucial. Here, one needs to be aware not only of our dual nature of matter and mind, but also of our dual - which is to say scientific and phenomenological ways - of tackling theoretical problems. In short, one may give a proper, dynamic account of human emotion and simultaneously recognize the advantage of thinking in dual - but not "dualistic" - registers.
\end{abstract}

Keywords: Descartes. Dualism. Emotion. Sartre. Spinoza.

a Universidad Diego Portales, Santiago, Chile. PhD, e-mail: daniel.oshiel@mail.udp.cl. Acknowledgement: I would like to thank the Fondecyt program by Conicyt for giving me the research time necessary to produce this publication. 


\section{Resumen}

Este artículo argumenta que una comprensión adecuada del tema del dualismo sólo puede lograrse a través de un análisis de la emoción humana. Para mi, no es una coincidencia que tres pensadores principales sobre el dualismo ya sean aparentes proponentes (Descartes), oponentes (Spinoza), o que tuvieran un estatus algo ambiguo (Sartre), también estuvieran muy involucrados en la comprensión de la emoción. En última instancia, una comprensión adecuada de la emoción muestra que el tema del dualismo no importa cuando se trata de nuestra vida cotidiana prereflexiva; el dualismo es un interés teórico que muestra cómo debemos necesariamente proponer dos reinos esenciales - uno de la naturaleza y otro de la conciencia - que, sin embargo, siempre están entrelazados en experiencias prereflexivas e inmediatamente vividas como la emoción. De esta manera, una comprensión adecuada de la emoción muestra que el dualismo no es un problema en el nivel de lo cotidiano, sino que ciertamente lo es en el nivel epistemológico y metafísico. En estos niveles, el dualismo es una herramienta esencial que debe ser entendida y utilizada adecuadamente si se quiere dar cuenta de la naturaleza humana desde un punto de vista teórico, donde es crucial evitar las confusiones entre las experiencias inmediatas y reflexivas, así como los puntos de vista en primera y tercera persona. Aquí, uno necesita ser consciente no sólo de nuestra naturaleza dual de la materia y la mente, sino también de nuestra dual - es decir, de las formas científicas y fenomenológicas - de abordar los problemas teóricos. En breve, uno puede dar un relato adecuado y dinámico de la emoción humana y simultáneamente reconocer la ventaja de pensar en registros duales, pero no dualistas.

Palabras clave: Descartes. Dualismo. Emoción. Sartre. Spinoza.

\section{Introduction}

Is seeing a chair, and thinking of a chair, the same experience? No. Is giving a first-person explanation, and a scientific explanation (cf. Goldie 2000: 1-2), of these experiences, also the same thing? No. This paper will show how such basic questions imply the issue of dualism at their very core, and how Descartes's support, Spinoza's dismissal, and Sartre's ambiguous stance to this issue can be helped through their mutual interest in human emotion.

First of all, it is well-known that Descartes was a dualist. Also well-known is Princess Elisabeth's challenge on this issue and how Descartes responded with his The Passions of the Soul. I will show that this book has been at best undervalued, at worst misunderstood; it was never intended to dispel the supposed "problem" of dualism when it comes to everyday life. Indeed, Descartes never found this to be a 
problem. The book, on the contrary, is a scientific investigation into our emotions (i.e. passions) and demonstrates our dual - but not "dualistic" - nature from a given investigative perspective.

Such an account remained unsatisfactory for Spinoza. Indeed, Spinoza's focus on passion for two whole parts of the Ethics this time explains our monistic being, which nevertheless contains two essential 'attributes', namely Descartes's extension and thought. In this manner, it is questionable how antagonistic Spinoza's thought ultimately is to Descartes's; perhaps the former pushed the latter's logic to its full limits, where an essential dual nature between matter and thought, bound through our emotions, is prevalent once again.

Sartre opens Being and Nothingness with a discussion of dualism, claiming that philosophy has been embarrassed by the issue for centuries. Such embarrassment can be resolved through a 'monism of the phenomenon', where emotion, once again, has a central place. Such monism threatens to lead to another dualism however, between brute nature (being-in-itself) and spontaneous consciousness (being-for-itself). A proper situation of Sartre's earlier account of emotion will here show that this is another formulation of the dual nature of human reality, meaning Sartre shares a decent amount of affinity with Descartes and Spinoza.

In this manner, a proper understanding of emotion shows that dualism is not an issue on the everyday level. Dualism is, however, an essential tool that must be understood and used properly if one is to give a thoroughgoing account of human nature from a theoretical standpoint - not least epistemological and metaphysical - where avoiding conflations between immediate and reflective experiences, as well as first-person and third-person standpoints, is absolutely crucial.

\section{Descartes}

Ryle's famous 'ghost in the machine' characterization ([1949] 2000: 17) of Descartes's thought is so well-known that it barely needs repeating. Damasio also has a whole book ([1994] 2005) on Descartes's gross 'error' of a total separation between body and mind, emotion and reason. If one would only read Descartes 
more closely on these issues however, one would see that the criticism is often unwarranted, or is even just plain wrong when one gets into the nuance of Descartes's different works, research interests and periods. Indeed, with Ryle at least, the two are actually much closer than one would at first think. Here is Descartes on the issue:

Nature [...] teaches me [...] that I am not merely present in my body as a sailor is present in a ship, but that I am very closely joined and, as it were, intermingled with it, so that I and the body form a unit. If this were not so, I, who am nothing but a thinking thing, would not feel pain when the body was hurt, but would perceive the damage purely by the intellect, just as a sailor perceives by sight if anything in his ship is broken. (M: 56).

This quotation seems to show that Ryle's ghost-machine characterization is exactly analogous to Descartes's insight that we obviously do not live our lives like some sailor (ghost) in a ship (machine); on the contrary, body and mind form an integral, fused unit in our daily lives.

The same quotation also shows, however, that Descartes does still draw a sharp distinction between body (machine, ship) and mind (ghost, sailor), even giving precedence to the latter. How, then, does one resolve this apparent tension, namely between a strict division between body and mind on the one hand, and a closely bound interaction between the two on the other?

There are some clues in the Meditations already. The fact that one can think of two distinct realms - namely res extensa and res cogitans - already makes 'me certain that the two things are distinct, since they are capable of being separated, at least by God' (M: 54). This, however, is a theoretical supposition, wherein God, if it so chose, could have completely material, or completely immaterial, beings. We know the former to be the case (e.g. rocks); the latter we have never experienced concretely, but this does not make it, for all that, theoretically impossible.

Then we have the factual reality regarding the pre-established union of mind and matter. This different register is what Ryle, Damasio and a whole host of others have all essentially missed in the criticism of Cartesianism. Here, due to 'my appetites and emotions' (M: 52) we always already experience thought as conjoined with a material element that is always already "mine" (ibid.). This is our body - or in phenomenological terms our 'lived body' (Leib) - where 'I could never be 
separated from it, as I could from other bodies' (ibid., my emphasis). In other words, our lived reality is always already one of a mind always already fused in and with a particular lived body. The two are never separate on this basic, lived level, even though they can be separated theoretically through conceptual analysis.

A problem then arises towards the end of the Sixth Meditation; Descartes characterizes 'the body of a man as a kind of machine' (M: 58) where, 'even if there were no mind in it, it would still perform all the same movements as it now does in those cases where movement is not under the control of the will or, consequently, of the mind' (ibid.). This passage does indeed seem to make some dualistic, ontological claims on the lived level. Here Descartes sees nothing but literally mindless machines that do much of what is required for survival and basic wellbeing merely through their inborn natural principles and mechanisms. The mind - namely reason and will - is, as a consequence, something completely other than the body, which is nothing other than mechanical appetites and the like. Thus, although clearly dual, Descartes's finish borders on really dualistic claims, namely a real, active distinction between raw, animal and mechanistic being on one hand, and a being governed and existing as mind, reason and will on the other.

This is a problem that needs a further focus, and it is to be found in Descartes's correspondence with Princess Elisabeth of Bohemia, culminating in Descartes's The Passions of the Soul - a text that much of the English-speaking scholarship on dualism has largely ignored (cf. Hoffman 1986; Shapiro 2006).

From the very beginning of their correspondence, Princess Elisabeth had one enduring preoccupation regarding Descartes's thought:

I ask you please to tell me how the soul of a human being (it being only a thinking substance) can determine the bodily spirits, in order to bring about voluntary actions. (C: 62 ).

This question broaches the issue of how mind and body interact. Descartes thinks that 'in view of my published writings, [this question is the one] one can most rightly ask me' (C: 63). His more detailed response is both informative and elusive, however: 
[T]here are two things about the human soul on which all the knowledge we can have of its nature depends: one of which is that it thinks, and the other is that, being united to the body, it can act on and be acted upon by it. I have said almost nothing about the latter, and have concentrated solely on making the first better understood, as my principal aim was to prove the distinction between the soul and the body. (C: 63-65, my emphasis).

Thus, Descartes somewhat dodges the question because he was concentrating, up to this point, on something else, namely the theoretical and intellectual distinction between res extensa and res cogitans. This point is further elaborated through his tripartite distinction of three 'primitive notions' (C: 65) and their corresponding domains of study: first there exists 'the notion of extension' (ibid.) through which one can investigate all that is to be known about body, shape and movement; second there exists the notion 'of thought' (ibid.) through which all that is to be known about 'the perceptions of the understanding and the inclinations of the will' (ibid.) can be investigated; and there exists, thirdly and finally and crucially, the notion of the soul's and body's 'union' (ibid.) wherein one investigates their interaction through the union's capacity for 'sensations and passions [i.e. emotions too]' (ibid.). These, then, are three fundamental ideas that should, according to Descartes, strictly delineate one's theoretical interests: study bodies through the notion of extension; study minds through the notion of thought; and study the interaction of body and mind through our experiences of sensation and passion and emotion. This does imply that there are some thoughts that do not, in theory, need a body; but it also implies that there are a number of experiences (sensations, passions and emotions) that cannot exist without a presupposed union of body and mind.

The Princess's question has not however been answered, at least not fully. This induces her to be more insistent (cf. C: 68). Descartes proceeds to dodge this issue once again by further elaborating upon his tripartite distinction: metaphysics is the discipline where one investigates the nature of thought (cf. C: 70); mathematics is the discipline where one investigates the nature of body (cf. ibid.); and 'life and ordinary conversations' (ibid.) teach us with regard to the mind and body's union, which is, under this formulation, 'one single thing' (C: 69). Taking such general distinctions on board, which are already crucial and helpful and have been overlooked, Descartes also did finally write a more dedicated work with regard 
to the issue: The Passions of the Soul. This was quite rightly dedicated to Elisabeth, as it attempts to address the precise question that Elisabeth refused to drop: how do mind and body interact? The answer, in short, is primarily through emotion, meaning the latter provides the felt foundations out of which all our other cognitions largely depend, whether directly or indirectly. This is an insight that Damasio later proposes (cf. 1999) himself, meaning it was his error, and not Descartes's, to not have seen or noticed it in the latter's last work.

The title to the opening article of The Passions of the Soul already shows that Descartes is now in a dual, but not dualistic, register: 'That what is a Passion with respect to a subject is always an Action in some other respect' (PS: Art. 1). In other words, the same phenomenon is a passion (i.e. passive) from the perspective of the mind in the sense that one undergoes it; but it is equally active from the perspective of the body in the sense that there is specific bodily activity, including but not limited to the brain. Thus a feeling of fear, for example, is something one (i.e. the mind) feels as a certain emotive quality; however, this also depends on, from perspective of the body, certain material actions that can be measured physiologically (e.g. a raised heart rate) - the two sides are two aspects of one and the same phenomenon.

We will see that Spinoza picks up this point in earnest, and in fact pushes it to its logical limit. Sticking with Descartes for now, after he deals with purely bodily functions he then proceeds to divide 'our thoughts' (PS: Art. 17) into 'two genera' (ibid.): 'actions of the soul' (ibid.) that always possess an active, volitional character; and 'passions' of the soul, which are felt passively - they are 'witnessed', undergone. Descartes goes on to make many more sub-distinctions; the one that interests us here is his threefold distinction of the passions (i.e. passive feelings) proper, which again another contemporary neuroscientist (J. Panksepp) repeats almost exactly (cf. Joldersma 2017: 147), calling them three main types of 'affects', without any reference to Descartes. Descartes calls them three types of 'perception' (cf. PS: Art. 22) that all have a certain bodily activity. On top of this, and crucially, the automatic way in which the soul - i.e. the mind - refers such action to differing realms determines their ultimate type, characterization and quality for us. Thus, firstly we have bodily actions (e.g. the retina picking up light) that the soul (i.e. the mind, 
consciousness) automatically refers to the external world (e.g. 'I see that cup'). These are our sense-perceptions (cf. PS: Art. 23). Then, secondly we have all bodily actions (e.g. a change in leptin and ghrelin hormone levels) that the soul automatically refers, by the nature of the union of body and mind, to the body ('I'm hungry'). Here are all our 'natural appetites' (PS: Art. 24). Finally, we have all the bodily activities (e.g. raised heartbeat and shaking limbs) that the soul automatically refers to itself ('I'm scared'). These are all of our passions in a stricter sense, or what we now call emotions (cf. PS: Art. 25).

The rest of the little treatise then goes on to give a quite exhaustive account of all of our various emotions, often describing the bodily involvement as well as its concomitant meaning to our souls (minds). The question of how, then, has been at least partially answered: mind and body communicate in their natural union through volitions (mind active) and passions (mind passive); of these latter the mind is almost always passive in the sense that it simply undergoes them by the very nature of this union. Such passions are further sub-divided into three main types: sensations, appetites and emotions. These three go a long way in explaining how it is possible that we are aware of an external world (sensations); that we are aware of our own body's needs (appetites); and how, finally, the soul ascribes various bodily activities to itself (emotions).

In order to further explain how bodily action transfers into mental feeling (and vice versa), we alight upon Descartes infamous pineal gland. Of course, a very unsympathetic reader - and Descartes has had more than most - would use this to have a laugh at Descartes, even to the extent of dismissing the rest of his account, as is still very common today. A sympathetic reader would, however, realize that one could update Descartes's vocabulary, replacing 'pineal gland' with 'brain' and terms like 'animal spirits' with 'nerve synapses' - and in this manner I believe his account is still surprisingly relevant and informative, even though it was penned so long ago.

Moreover, more generally Descartes was dealing with perhaps one of the most difficult issues in human knowledge. This is because one can always be left with the problem of how precisely mind and matter interact: if one is a staunch materialist, then one flatly ignores the everyday reality of thought, which abides 
differing laws to matter (e.g. unextendedness); the inverse could be said of any staunch idealist; and to hedge between the two still means using matter and mind as theoretically different things. Nowadays in neuroscience, claiming mental life to be a mere epiphenomenon of physical activity (brain) is not to solve the issue at all - it merely emphasizes the role of one privileged piece of matter over all else, as if the brain could do anything on its own, without a body, mind and an environment. And idealism does the reverse, reduces matter to mere images of thought. Both of these, as well as a more compromising position, are still all thinking in dual registers, and are just giving precedence to one extreme or neither. In fact, it is our human condition that always makes us think in terms of matter and mind - we cannot think otherwise - precisely because we are always already made of both; they are all we know and can know. This becomes even clearer with Spinoza.

\section{Spinoza}

Spinoza of course was a monist. I intend to show, however, that he still has a strongly dual and Cartesian bent, which is not even to mention the fact that his monism brings a new challenge of its own.

Spinoza's monism is as blue as sky: there is one infinite substance (God or Nature) that eternally possesses an infinite amount of attributes (cf. E: 75). Spinoza, however, goes on to focus on only two attributes, precisely because humans only have cognitive awareness of these two, such is our limited nature. Which are they? Thought (mind) and extension (matter) of course. Indeed, our universe is made up of so many particular modes which, conceived under the attribute of extension, are bodies; conceived under the attribute of thought, are ideas (cf. E: 113). There is only one substance however, which has the consequence that nothing exists besides this and modes (cf. E: 86), with the latter being wholly dependent upon the former. In this way, nothing exists but Nature and its infinite number of particular manifestations that are only particular modifications or affections (i.e. modes) of such a primordial and eternal Nature.

Descartes's theoretical dualism has hereby been transformed into a theoretical monism with, nonetheless, two dominant attributes - when considering 
human reality at least. Indeed, conceiving any other attribute seems impossible from our limited standpoint, even though, logically for Spinoza, God must contain an infinite number. For us mere human mortals here and now then, there is already an important consequence: if one is to think correctly then one has to do so either in the register of extension, or in the register of thought. For Spinoza it is crucial not to muddle the two because, by their very conception, only like can limit like: 'a body is not limited by a thought; nor a thought by a body' (E: 75). This means to describe thought in material terms (materialism), or to describe matter in mental terms (idealism), are both high absurdities. In other words, one must either analyze the matter and its operations or thought and its operations. Both would have the result of couching one's analyses in their proper terms (bodies and ideas respectively) terms which, nevertheless, ultimately refer to the same reality from the perspective of an all-encompassing Nature.

Hereby we see the dual theoretical emphasis in Spinoza's thought, even though ultimately all is one. Here one may ask: How does this affect his conception of mind-body interaction? This is answered once again through a long and detailed study of emotion, which takes up a great deal of the Ethics. In short, Spinoza's ultimate trick is to claim that mind and body do not really "interact", nor do they need to; they are the exact same thing, conceived now in one way, now in another. For example, fear can be felt with more of a mental focus through a particular scared feeling; but it can also and at the same time be felt more physically and bodily through awareness and descriptions of shaking limbs, raised adrenaline and heart rate, etc. For Spinoza there is one reality to all of this, just with two - or we may say a dual - dimension: the perspective of mind and its conscious ideas, and the perspective of matter with its physical bodies and activities. This means any mental dimension necessarily has a corresponding physical one and vice versa. This is the absolute parallelism required for his monism, which again has one ultimately reality that is nevertheless expressed for us in a dual manner, through the aspects of matter and bodies, and of mind and ideas.

This subtle theoretical alteration resolves a number of issues, not least the awkward question of interaction in the first place. However, it also creates some 
new issues, not least the issue of absolute parallelism, as well as the remaining dual notion of activity and passivity, the latter of which is another Cartesian remnant.

In an important proposition, Spinoza states that ' $[\mathrm{t}]$ he object of the idea constituting the human mind is the body, or, a certain actually existing mode of extension, and nothing else' (E: 124). What does this mean? Well it means, by nature, that the mind's most immediate and immanent idea of an object is indeed its own body - the two, if one studies Nature properly, go necessarily together such that 'man consists of mind and body, and that the human body exists as we sense it' (ibid.). Spinoza then goes on to analyse the Cartesian-inspired theme of the socalled 'union' (E: 125) between these two. Here Spinoza states three important propositions: ' $[\mathrm{t}]$ he human mind does not know the human body, nor does it know that it exists, except through the ideas of the affections by which the body is affected' (E: 135); '[t] he human mind perceives, not only the affections of the body, but also the ideas of these affections' (E: 137); and '[t] he mind does not know itself, except in so far as it perceives the ideas of the affections of the body' (ibid.). Thus, knowledge of the body is wholly dependent upon consciousness of the former's affections; awareness of these latter also simultaneously and automatically produce ideas of such affections; and this is the only way in and through which the mind can know itself, too. This paints a picture where the 'union' is a real, pre-established one, meaning it seems inconceivable that the two - in humans at least - could exist otherwise.

Spinoza then proceeds to give a more concentrated account of (human) emotion. Much of this account centres around the distinction between adequate and inadequate causes, and the subsequent delineation between passive ('passions') and active emotions: 'I call that an adequate cause whose effect can be clearly and distinctly perceived through itself. I call that an inadequate, or, a partial cause whose effect cannot be understood through itself alone' (E: 164). God necessarily contains - or is - all adequate causes, and we are only active when what we do comes wholly and completely from a rational understanding of the situation (cf. E: 211). In short, we are only active when we partake in Spinoza's rational God. This means that the vast majority of emotions are indeed passions; passion occurs precisely when 'something occurs in us, or when something follows from our nature, of which we 
are only a partial cause' (E: 164). Along with this, Spinoza also defines emotions, more generally, as 'affections of the body by which the body's power of acting is increased or diminished, helped or hindered, and at the same time the ideas of these affections' (E: 164). Thus there is a direct and absolute parallelism between the 'affections of the body' and the simultaneous 'ideas of these affects' in every emotive experience (and in all experiences, for that matter).

On top of this, we have the active, rational emotion of 'fortitude' (E: 211), which is divided into 'courage' (ibid.) and 'nobility' (ibid.). 'Courage' is 'the desire by which each person endeavours to preserve his being in accordance with the dictate of reason alone' (ibid.); 'nobility' 'the desire by which each person, in accordance with the dictate of reason alone, endeavours to help other men and join them to him in friendship' (ibid.). These are the only fully active, i.e. purely rational emotions; all others are passions, of which two basic ones (desire and pleasure) increase one's power; and another, final basic one (pain) decreases one's power (cf. 173). All other passions and emotions stem from these three basic passions for Spinoza; and when we act 'with the dictate of reason alone', desire and pleasure can transform into fortitude and its two species.

Most of the time, however, there is a passive element, which means much of our life is occupied with a to and fro between partially increasing in power through positive passions, and partially decreasing in power when we undergo negative feelings. This means the dual idea of passivity and activity pervades Spinoza's account of human nature, which is nothing other than a constant undulation between increasing and decreasing in (rational) power.

What of the mind and body's supposed interaction, then? Well, as already noted, for Spinoza no interaction is required, for these two aspects are ultimately different expressions of one and the same reality:

$[T]$ he mind and the body is one and the same thing which is conceived now under the attribute of thought and now under the attribute of extension. From this it comes about that the order, i.e. the interconnection, of things is one, whether Nature is conceived under this or that attribute, and consequently that the order of the actions and passions of our body is simultaneous in nature with the order of the actions and passions of the mind. (E: 166). 
Thus, a passion or emotion is one and the same thing in both registers; one simply changes the expression (physiological or mental) depending on which register one is theorizing in. Here there is indeed an absolute parallelism: ' $[\mathrm{w}]$ hatever increases or diminishes, helps or hinders, our body's power of acting, the idea of that same thing increases or diminishes, helps or hinders, our mind's power of thinking' (E: 173) - there is an absolute parallelism whereby some mental or bodily activity necessarily (i.e. logically in Spinoza's system) has a simultaneous counterpart in the other register. Thus, as already described my feeling of fear, in mental terms, is nothing other than the raised heartbeat and the like, with the latter merely being the physiological explication of the same thing. One does not "cause" the other; they are the very same thing expressed in two different ways, under two different conceptual aspects, matter and mind.

Although ontologically monistic (cf. Wider 2013: 557), Spinoza's system does state that each mental or physical event must have an exact correlate or counterpart in the other register. Whether such absolute parallelism is actually the case is probably impossible to prove empirically, especially given our limited natures. Nonetheless, it follows by necessity from Spinoza's rationalistic system, which is a monistic one that nevertheless adopts and transfigures the primacy of two, dual aspects of our human nature: thought and matter. All this considered however, the way Spinoza openly deals with the study of human emotion from a 'geometrical' (E: 163), committed rationalist standpoint can leave one with a nagging feeling that may be addressed through the work of Sartre.

\section{Sartre}

Sartre begins Being and Nothingness by claiming that the history of philosophy has been 'embarrassed' (BN: 1) by a number of pervasive and stubborn dualisms that now, thanks to phenomenology, can be replaced by the monism of the phenomenon' (ibid.). Sartre articulates a number of dualisms; most relevant for us here is the following passage:

Force, for example, is not a metaphysical conatus of an unknown kind which hides behind its effects (accelerations, deviations, etc.): it is the totality of these effects. Similarly an electric current does not have a secret reverse side: it is nothing but the totality of the physical-chemical actions (electrolysis, the incandescence of a carbon filament, the displacement of the needle of 
a galvanometer, etc.) which manifest it. None of these actions alone is sufficient to reveal it. But no action indicates anything which is behind itself: it indicates only itself and the total series $^{1}$ (ibid.).

Here one of Sartre's targets is clearly Spinoza; Sartre denies a 'metaphysical conatus' at work on some "deeper level" and instead claims that all is played out on one phenomenological level, even if the 'total series', by definition, is never actually given in any single aspect, mode or phenomenon. This leads Sartre to conclude that there is not - or at least there should not be - any strict distinction between 'being and appearance' (ibid.); being is always in the appearance(s); 'the being of the existent is exactly what it appears'2 (ibid.). In this manner, 'essences' - i.e. the true nature of things - do not lie behind phenomena in some noumenal hinterland; they can be studied and captured through the phenomena themselves (cf. BN: 2-3). Such is one of the main tenets of phenomenology.

After having critiqued other aspects of dualism quite quickly, Sartre asks if we have not simply 'converted them all into a new dualism: that of finite and infinite' (BN: 3). Here the idea is that the essentials of the phenomena lie in the phenomena themselves - and yet the totality of any given phenomenon cannot actually be present at any given point in time. Thus, although Sartre denies a kind of noumenal hinterland, there is a distinction between the finite phenomenon, given here and now, and the inexhaustibility of studying this phenomenon because, given the nature of perception, any given object can never be totally captured in any given instant or from any one perspective. Indeed, because perception is necessarily perspectival (another main tenet of phenomenology) there are always finite things that nevertheless always harbour an infinite possible series of further appearances.

Phenomenology's task is, then, to establish essential structures and categories through this unending study of phenomena, from perception to

\footnotetext{
${ }^{1}$ Translation modified - « La force, par exemple, n'est pas un conatus métaphysique et d'espèce inconnue qui se masquerait derrière ses effets (accélérations, déviations, etc.) : elle est l'ensemble de ces effets. Pareillement le courant électrique n'a pas d'envers secret : il n'est rien que l'ensemble des actions physico chimiques (électrolyses, incandescence d'un filament de carbone, déplacement de l'aiguille du galvanomètre, etc.) qui le manifestent. Aucune de ces actions ne suffit à le révéler. Mais elle $n^{\prime}$ indique rien qui soit derrière elle : elle indique ellemême et la série totale. » (EN : 11).

${ }^{2}$ The English is rather awkward here, hence the French: « l'être d'un existant, c'est précisément ce qu'il paraît. » (EN : 12).
} 
imagination, from concrete things to images and conceptual ideas and truths. Now, although Sartre more or less drops the issue of dualism in the rest of his work, I do indeed see a dual register throughout his thought in general. The most basic is that conceptual, but also ontological, distinction between two absolutely fundamental types of being. First, 'being-in-itself' (l'être-en-soi) is the being of things, of matter and the like; these things simply 'are what they are', like a rock is a rock, for they coincide absolutely with themselves in the form of a full 'plenitude of being' (BN: 17) that is not noumenal, but 'transphenomenal' (cf. BN: 6). Second, there is another type of existence that is of a diametrically opposed ontological nature: this is 'being-foritself (l'être-pour-sol), which is Sartre's ontological formulation of consciousness. Consciousness, unlike the material realm, never coincides with itself; consciousness is essentially a non-coincidence whereby, due to this very fissure, it allows beings which it is not to appear to it as such. Herewith we have another main tenet of phenomenology: '[a]ll consciousness, as Husserl has shown, is consciousness of something' (BN: 7) - consciousness is always consciousness of something it itself is not, namely being-in-itself and its particular manifestations.

We thus have a dual distinction at work in the heart of Sartre's work: a simple, brute form of existence that simply 'is what it is' and is in need of no other being to be (this is Sartre's realism - cf. BN: 46); and another form of existence which exists as consciousness of (aspects of) the former.

In this manner, although Sartre begins by replacing previous dualisms with a 'monism of the phenomenon', his analyses are nevertheless pervaded by many important dual distinctions, consisting of various poles that are constantly intertwined in a complex phenomenological dynamic. This can be seen more specifically in Sartre's earlier account of emotion. Here, each mode of consciousness (perceptive, emotive, imaginative) has different laws, although they all share that most fundamental of phenomenology, intentionality (consciousness of...). Emotive consciousness thus has particular laws in its own right, which, when it is studied in its full immediacy, one sees that it is a 'magical' engagement with the world (cf. O’Shiel 2019, particularly chapter two).

Sartre's Sketch defines 'magic' as 'an irrational synthesis of spontaneity [i.e. activity] and passivity' (STE: 56). A smiling face (cf. ibid.), for example, is both 
'passive' (i.e. a thing, an in-itself) because it is a physical phenomenon that abides certain physical laws (movements of certain facial muscles and the like); and yet it is also 'active' (i.e. spontaneous) in the sense that such a smile emanates from the absolutely spontaneous nature of the particular person - of a particular conscious subject. Such a simple example already shows how emotion involves a strange mixture of both activity (conscious spontaneity) and passivity (certain physical laws) in one and the same phenomena (a smiling face). This theory is thus akin to Spinoza's (and even Descartes's), whereby the study of emotion is aware of dual registers, one gleaned from the immediate nature of consciousness, the other observed from the immediate bodily manifestations of such psychical undergoings. In fact, all three philosophers show that emotion is necessarily a psychophysical phenomenon; emotion is utterly inconceivable without body and mind always already functioning together - they are always already lived as a piece in our everyday lives, completely fused. We then need such analyzed concepts to explicate them more fully on the theoretical level, although the ever-present danger here is that one will theorize in such a manner that loses sight of the actual lived experience which always already involves both registers, both matter and mind together in a highly close and complex dynamic.

Although there are two main types of emotion for Sartre - one where the emotion is actively lived in the sense that it stems from the subject (e.g. shouting at someone); and another where it is passively lived because the world, always peopled by others, appears to us as lovely, shocking, horrible and the like (e.g. taking fright from someone or something) - because of the law intentionality there is nevertheless always a dynamic between these two types (the first centrifugal; the second centripetal - cf. O’Shiel 2019: 37-40). Sartre admits as much when he states that 'the majority of our emotions are impure'3 (STE: 58) - i.e. mixed with aspects of both consciousness and world. Thus, although an internal trigger can constitute 'active' emotions (e.g. a bad mood - cf. O’Shiel [2016] 2017), and an external one 'passive' ones (e.g. a scary thing); and although both are only possible because of

${ }^{3}$ Translation modified - «la plupart des émotions sont impures » (ETE : 111). 
the original spontaneity (i.e. activity) of Sartrean consciousness that is nevertheless always already engaged with the world and its objects and people, it is precisely in emotion that psychophysiological incantations blend the two poles.

One can thus see that Sartre has picked up the dynamic between activity and passivity in emotion, although it is no longer (directly at least) conditioned by a rationalistic backdrop which seeks to make everything rational "active", and everything that is not "passive". No, for Sartre the issue concerns more from where the main emotive movement emanates - if it is from consciousness it is considered active for the most part; and if it is mainly triggered by the world and its objects then the emotion is undergone in a more passive manner. Both varieties necessarily involve a Leib, a 'lived body' however. In fact, emotion, when properly studied, is for Sartre never "rational" in the strict sense of the term, for it is of a completely different - namely magical - register, a transformation of a pragmatic attitude towards the world into one where emotive qualities come to inhere in things (e.g. a 'stupid' computer when annoyed at it) that these objects do not originally contain on their own (cf. again chapter two of O'Shiel 2019). In fact, this 'register' can be said to be the primary one, in that young children, who experience many quite pure emotions, have to learn rationality as they grow up.

Sartre does, however, maintain some version of the aforementioned rationalistic backdrop in his formulation of this 'pragmatic attitude'. Indeed, it has already been suggested that Sartre's two sub-categories of emotion boil down to one fundamental dynamic: emotion is a 'transformation of the world' (STE: 39) wherein a standard, pragmatic attitude is thwarted, suspended, blurred or even breaks down. In the pragmatic attitude, 'the world of our desires, our needs and of our activities, appear to be all furrowed with strait and narrow paths leading to such and such determinate end' (STE: 39). In short, we are (more or less) in control, and the way of getting where or what we want is neatly laid out. However, because the world is difficult (e.g. an annoying person), as well as unpredictable (e.g. someone surprising you), there are many scenarios in which such 'paths' are not so straightforward. Additionally, because we have already seen that the absolute spontaneity of consciousness never ceases (except in death, and to some extent in sleep; precisely the cases where consciousness of the world is eradicated (death) or 
minimized (sleep)) - even when one may wish it to do so - this has the consequence that when problems, difficulties and surprises arise, as they often do, then the incessant transcendent process of consciousness going to and from the world can only be monitored and safeguarded, but never stopped. Thus, when such issues arise the projects and desires of an individual have to be lived through in some way or other. When more pragmatic and practical options are barred or not liked, emotion results. Here, consciousness spontaneously manifests itself in a strong bodily manner that tries, through such manifestation, to transform the world in a way that perpetuates the continuous transcendent activities of such consciousness. In short, emotion transforms a world of determinism into a world of magic, whereby actions are enacted in order for consciousness to somehow deal with the frustration or impossibility of living out a particular project right then and there in all its practical facets.

This is the kernel of Sartrean theory on emotion: whether we tear up mathematical problem in frustration (cf. STE: 25-26); strike someone in anger; or take fright from something unexpected, we do so in an absolutely spontaneous manner that pre-emptively suspends more calm and collected (re)actions, which, precisely through the emotion, are no longer desired or possible. This is the case in positive emotions like joy (cf. STE: 46) too, where the emotion overflows a given state of affairs by celebrating in a manner that captures all that is blissful about one's existence, thereby bracketing more pragmatic considerations that such states may also harbor.

This means that when emotion is studied phenomenologically in its fully immediacy, one sees dynamic and essential aspects at work that remain off-limits to the scientific 'spirit of seriousness', which focuses primarily on the facts (facial expressions and the like). For indeed, causally speaking it impossible to have past, present and future all at once. Nevertheless, magically speaking (which is to say in emotions such as joy) past efforts can be presently celebrated in a manner where future practical concerns are suspended. This is to say that emotions are not static psychical states simply "in the now"; they are lived, temporalized and temporalizing activities that immediately manifest our most cherished values, hopes and fears, past, present and future. Such values, hopes and fears, moreover, are always already 
structured by an emotive being that demonstrates a dual dynamic of our nature that is both mental and material - these two elements are always of a piece in our everyday, fused lived experiences, as I believe the analyses of all three thinkers have now shown.

\section{Conclusion}

Such analyses lead me to conclude that it is important to know in which register (or registers) one is theorizing, for if unaware it can lead to various rather serious misunderstandings.

Firstly, I have claimed that Descartes's distinction between res cogitans and res extensa was a theoretical one that had a different aim from understanding mind-body interaction in actual, living human beings. In this manner Descartes did not enact a 'category-mistake', but actually had a third category (cf. Hoffman 1986: 341; Schmaltz 1992: 288; and Shapiro 2006: 271) of which people like Ryle and Damasio were unaware, and with which they would have shared much more affinity than they thought. For this latter register one has to look primarily to Descartes's The Passions of the Soul, where a dual, but not dualistic, study is undertaken in order to show that what is active in passion and emotion is physical, bodily activity which, quite simultaneously, is automatically and passively experienced by the mind as its own and various emotive feelings. Body and mind here are thus two conceptual poles of the same fundamental, fused dynamic. In short, emotion would not exist were it not for the pre-established union of the living human being, meaning understanding emotion also puts the issue of dualism more in its proper epistemological and metaphysical place, as a theoretical issue for enquiry and investigation, and never actually a problem within everyday pre-reflective lived experience.

Spinoza, secondly, eluded the question of 'how' by affirming that there is only one reality of which we are always nevertheless aware of in two different registers, extension and thought. For Spinoza, as for Descartes, it was vital to understand in which register one is thinking, for otherwise one is led into grave misunderstandings. The dominant theme in Spinoza on emotion is a distinction 
between increase and decrease in power: active emotions, of which there are few, are when one is living wholly by the dictates of reason; all the rest are passions, or passive emotion, in which we only have inadequate ideas and thus experience relatively confusedly. For Spinoza, because there is only one reality but nevertheless two registers or expressions of that same reality, there is an absolute parallelism between mind and body, which brings up the curious and perhaps unsolvable question as to whether there in fact is a physical correlate for every mental event, and vice versa. Nevertheless, the study of emotion here once again shows that matter and mind are not only dynamically fused but are ultimately the same thing in Spinoza's monistic system.

Sartre, for all his dismissals of dualism at the beginning of Being and Nothingness, formulates his own system that is nevertheless heavily indebted to his predecessors in certain fundamental respects. Indeed, Sartre's two main ontological realms - being-in-itself and - for-itself - correlate, roughly but not exactly, to Descartes's (and even Spinoza's) distinction between a realm of nature that can be simply and scientifically studied for what it is (including all of its observable facts); and a realm of thought that is of an entirely different nature (at least for Sartre) to the former. In Nagel's terms ([1986] 1989), the trick then is to objectively describe subjectivity without losing the latter's uniqueness. This is no easy task; Sartre develops a very subtle notion of consciousness, which abides different ontological laws to being-in-itself to the extent that, through experiences like emotion as well as its inherent dynamic of magic, we come to see that Descartes and Spinoza were perhaps caught up in an overly 'geometric' spirit of their time. Indeed, although Descartes and Spinoza were quite radical in their own respects, Sartre's thought still presents us with a new radicality: if one wishes to study the physical world in a scientific manner, all well and good, for the nature of being-in-itself is conducive to that; if one, however, wants to really understand the nature of human emotion, among other things, then one cannot reduce one's studies to so many empirically observable facts. No: here, to capture the essence of human emotion as it is actually lived, one needs to enter an attitude that analyses our immediate, pre-reflective experiences and, through such observations, come to laws and truths that, although 
not in the slightest contrary to facts, provide us with a depth and richness that these latter could never attain by themselves.

In this manner, 'understanding dualism' maintains a distinction between a pre-reflective level where there is an incessant and highly complex lived dynamic that always already presupposes matter and mind as infused and lived together. On the other side, when one wishes to reflect more abstractly, one can take up and theorize upon this dynamic, or even focus on the extremes of pure matter on one end, and pure mind on the other. There are disciplines that knowingly focus on matter (e.g. physics); disciplines that knowingly focus on mind (e.g. logic); and disciplines where perhaps the very distinction loses validity or comes full circle (e.g. mathematics).

A main message here is that if one wishes to study human reality - and not least human emotion - as it is actually experienced and lived, then it is erroneous to materialize the mind (materialism) or idealize matter (idealism). Indeed, precisely because the two poles of matter and mind are always already presupposed in our actual lived experiences, if one wishes to understand this dual nature one must take both of them equally into account. In my opinion, phenomenology is the best method so far to do this, for it does take equal account of our dual - but not dualistic - lived being. Sartre obviously did this, along with many other phenomenologists. However, even Descartes and Spinoza, although very much involved in many other more theoretical registers and issues, are not so far removed from such a phenomenology when they actually turn their attention to the realm of human emotion - one main instance of our fused being, which shows just how intricate and subtle our lived experiences in fact are.

\section{References}

Damasio A. R. [1994] (2005). Descartes' Error. Emotion, Reason, and the Human Brain. Penguin Books.

Damasio A. R. (1999). The Feeling of What Happens: Body and Emotion in the Making of Consciousness. New York: Harcourt.

Descartes R. [1641, siglum: M] (2011). Meditations on First Philosophy, with Selections from the Objections and Replies. Cambridge University Press (trans. John Cottingham). 
Descartes R. [1649, siglum: PS] (1989). The Passions of the Soul. Indianapolis and Cambridge: Hackett Publishing Company (trans. Stephen Voss).

Princess Elisabeth of Bohemia, and Descartes R. [1643-1649, siglum: C] (2007). The Correspondence between Princess Elisabeth of Bohemia and René Descartes. Chicago and London: University of Chicago Press (trans. Lisa Shapiro).

Goldie P. (2000). The Emotions. A Philosophical Exploration. Oxford: Clarendon Press.

Hoffman P. (1986). The Unity of Descartes's Man. The Philosophical Review, 95(3), 339370.

Joldersma C. W. (2017). Overcoming Neuroscience's Lingering Dualism in Cognition and Learning via Emotion: Freedom, Phenomenology, and Affective Neuroscience. In Philosophy of Education 2014 (ed. Michele Moses). Urbana, Illinois: Philosophy of Education Society, 145-153.

Nagel T. [1986] (1989). The View from Nowhere. New York and Oxford: Oxford University Press.

O’Shiel D. [2016] (2017). From Faint Mood to Strong Emotion: Merging Heidegger and Sartre? Philosophia 42, 1575-1586.

O’Shiel D. (2019). Sartre and Magic. Being, Emotion and Philosophy. London, New York et al.: Bloomsbury Academic.

Ryle G. [1949] (2000). The Concept of Mind. Penguin Books.

Sartre J.-P. [1938, sigla: STE/ETE] (2002/2009). Sketch for a Theory of the Emotions. London and New York: Routledge (trans. Philip Mairet)./Esquisse d'une théorie des emotions. Hermann.

Sartre J.-P. [1943, sigla: BN/EN] (2005/2012). Being and Nothingness - An Essay on Phenomenological Ontology. London: Routledge (trans. Hazel E. Barnes)./L'être et le néant - essai d'ontologie phénoménologique. Paris : Éditions Gallimard.

Schmaltz T. M. (1992). Descartes and Malebranche on Mind and Mind-Body Union. The Philosophical Review, 101(2), 281-325.

Shapiro L. (2006). Descartes's Passions of the Soul. Philosophy Compass, 1(3), 268-278.

Spinoza B. [1677, siglum: E] (2009). Ethics. Oxford University Press (trans. G. H. R. Parkinson).

Wider K. (2013). Sartre and Spinoza on the nature of the mind. Continental Philosophy Review 46(4), 555-575. 